\title{
MUDANÇAS NA VEGETAÇÃO RIBEIRINHA ASSOCIADA A FORMAS E PROCESSOS GEOMORFOLÓGICOS EM UM SETOR PERIURBANO DE BAHÍA BLANCA (ARGENTINA)
}

\author{
Marilina González ${ }^{1}$ \\ Verónica Gil² \\ Jorge Gentili ${ }^{3}$
}

Resumo: O objetivo deste trabalho é estudar as interações recíprocas entre as mudanças geomorfológicas de origem antropogênica e a distribuição e tipo de cobertura vegetal ripária em um setor da bacia inferior do riacho Saladillo de García. Para isso, foi realizada uma análise visual multitemporal de imagens de satélite de alta resolução espacial onde, a partir da seleção das unidades amostrais, foram identificadas as alterações mais significativas na vegetação da área. Os resultados obtidos indicam que as variações mais significativas no tipo e cobertura da vegetação foram identificadas nos setores onde foram registradas as maiores intervenções antrópicas na geomorfologia fluvial do riacho. Através desta análise, foi identificado uma interação entre os processos hidrogeomorfológicos e a distribuição da vegetação em que em alguns casos a mata ciliar foi o indicador de campo para interpretar as intervenções antrópicas na geomorfologia fluvial.

Palavras-chave: dinâmica fluvial; geomorfología; vegetação; periurbano; Bahía Blanca.

\section{CHANGES IN RIPARIAN VEGETATION ASSOCIATED WITH FORMS AND GEOMORPHOLOGICAL PROCESSES IN A PERI-URBAN SECTOR OF BAHÍA BLANCA (ARGENTINA)}

\begin{abstract}
The objective of the work is to study the reciprocal interactions between geomorphological changes of anthropogenic origin and the distribution and type of riparian vegetation cover in a sector of the lower catchment of the Saladillo de García stream. For this, a multitemporal visual analysis of satellite images of high spatial resolution was carried out where, from the selection of sampling units, the most significant changes in the vegetation of the area were identified. The results obtained indicate that the most significant variations in the type and coverage of vegetation were

\footnotetext{
Doutoranda em Geografia pela Universidad Nacional del Sur (CONICET) . Email: marilina.gonzalez@uns.edu.ar

2 Professora Adjunta do Departamento de Geografía e Turismo. Universidad Nacional del Sur (UNS). Email: verogil@uns.edu.ar

3 Professor Adjunto do Departamento de Geografía e Turismo. Universidad Nacional del Sur (UNS). Email:
} jogentili@uns.edu.ar
\end{abstract}


identified in the sectors where the greatest anthropogenic interventions were recorded in the fluvial geomorphology of the stream. Through this analysis, an interaction between the hydrogeomorphological processes and the distribution of the vegetation was verified, in which in some cases the riparian vegetation was the field indicator to interpret the anthropic interventions in the fluvial geomorphology.

Keywords: fluvial dynamics; geomorphology; vegetation; peri-urban; Bahía Blanca.

\section{INTRODUCCIÓN}

En los estudios sobre dinámica fluvial existen numerosas investigaciones vinculadas principalmente a la geomorfología, hidrología y a las condiciones climáticas, ya que son consideradas variables fundamentales en el análisis de las cuencas hidrográficas (Muñoz-Pedreros, 2004; Massolo, 2015; Duarte y Sousa Lopes, 2021). Por diferentes motivos en estos estudios se ha considerado a la vegetación como una variable independiente en este análisis, por ello, es frecuente encontrar trabajos geográficos que realizan descripciones sobre la composición, tipología y distribución de la misma desde una mirada unidireccional sin considerar el componente relacional de los elementos (Mazzola et al., 2008; Cabrera-Amaya y Rivera-Díaz, 2016; Cabrera-Amaya et al., 2020; Guitián, Vázquez y Sañudo, 2020; Beato Bergua et al., 2021). En el proceso hidrogeomorfológico, tanto el relieve como drenajes y suelos cambian continuamente sus características, haciendo más o menos favorable las condiciones para la instalación de las distintas comunidades vegetales.

A su vez, la vegetación constituye un elemento clave en el funcionamiento del sistema fluvial, no solo por las múltiples interacciones que se desarrollan en el canal entre el flujo hídrico y la vegetación, sino también por la importante función estabilizadora que posee en las zonas de ribera (Sandercock, Hooke, y Man, 2007; Istanbulluoglu y Bras, 2005; Marston, 2010; Han y Brierley, 2020; Baniya, et al., 2020; Tomsett y Leylan, 2020).

Diversos autores plantean la necesidad de un estudio integrado bajo una perspectiva fitogeomorfológica que tenga en cuenta las interacciones que se desarrollan entre la distribución de la vegetación y la morfología del terreno y sus procesos (Passos, 1977; Perucca, Camporeale, y Ridolfi, 2007; Corenblit et al., 2009; Tal y Paola, 2010; Corenblit et al., 2011; O'Donnell, Fryirs, y Leishman, 2015; Surian et al., 2015; González et al., 2020; Nallaperuma, y Asaeda, 2020; Jerin, 2021). En un artículo de revisión a cerca de avances recientes en el campo de la biogeomorfología, Corenblit et al. (2009) plantean una nueva perspectiva en la interfaz entre geomorfología y ecología para ampliar las interacciones simples 'unidireccionales' entre biota y geomorfología y mejorar la comprensión de retroalimentaciones que controlan la resiliencia y resistencia biogeomorfológicas. Proponen que la biogeomorfología ahora comience a compartir conceptos y teorías con la ecología para ayudar a desarrollar nuevos modelos de interacciones recíprocas abióticobióticas.

Por su parte, Hupp, Dufour y Bornette (2016) analizaron las distintas formas en las que se puede utilizar a la vegetación como una herramienta para la interpretación geomorfológica. Una de ellas tiene que ver con la interpretación de los patrones de distribución de especies como respuesta a las condiciones hidrogeomórficas predominantes y el papel que juega la vegetación en los caudales y los procesos de erosión y deposición posteriores. Hupp y Osterkamp (1996) estudiaron las relaciones entre la vegetación y los procesos hidrogeomorfológicos para los arroyos 
representativos de cuatro áreas con características ambientales distintas de los Estados Unidos. Concluyeron que los patrones de vegetación y la distribución de especies podrían estar controlados por distintos procesos hidrogeomorfológicos relacionados con la frecuencia, duración e intensidad de las inundaciones, la variación en procesos geomorfológicos fluviales (ciclos de degradación y agradación) y los patrones de disponibilidad de agua.

Del mismo modo, Sandercock et al. (2007) proponen un análisis integrado de las interacciones que se dan entre las variables que intervienen en los procesos fluviales (vegetación, magnitud del flujo hídrico y suministro de sedimento) y afirman que las variaciones en el confinamiento de un canal y su efecto en el poder de la corriente puede tener una fuerte influencia en la distribución de la vegetación. Brookes, Hooke y Mant (2000) elaboran un modelo de simulación de cambios en canales efímeros de cursos fluviales de la región Mediterránea para determinar cómo la vegetación interactúa como un elemento más dentro del análisis del sistema hidrográfico. Siguiendo esta perspectiva, Ollero et al. (2011) sostiene que, si en un curso fluvial hay pocas crecidas, se desarrolla la vegetación que reduce la erosión y fija los sedimentos, por lo que si la vegetación se instala y madura, el cauce se estabiliza.

En Argentina, si bien existen numerosas investigaciones vinculadas a la geomorfología y la vegetación, el foco ha estado colocado en su mayoría en un análisis descriptivo individual de los elementos. Sin embargo, autores como Giorgis, Cingolani, y Cabido (2013), Vilan Ova y Prieto (2012) y Flores, Suvires, y Dalmasso (2015) realizan abordajes en los que contemplan las mutuas relaciones entre ambos factores.

En la cuenca baja del arroyo Saladillo de García, sobre la que se desarrolla el periurbano noroeste y oeste de la ciudad de Bahía Blanca, los cursos fluviales están caracterizados por ser muy angostos (entre 1 y 3 metros), muchos de ellos intermitentes, tener caudales bajos e irregulares producto de la variabilidad espaciotemporal de las precipitaciones y por presentar llanuras de inundación muy amplias. En al área de estudio, se han identificado cambios asociados al avance del ambiente urbano (modificaciones antrópicas directas e indirectas en las formas y procesos fluviales) que le han otorgado una nueva dinámica al espacio fluvial (González, 2018; González, Gentili, y Gil, 2020). En su estado natural, las zonas ribereñas suelen estar cubiertas de vegetación asociada al tipo de suelo y al clima zonal (Ollero et al., 2011).

Sin embargo, bajo un contexto de cambio, el resultado será una nueva vegetación cuasi-equilibrada asociada a la nueva dinámica (Auble, Friedman, y Scott, 2015; Hupp, 2016). El sector de estudio fue escogido porque en él se han registrado intervenciones en las formas y procesos fluviales asociados a la actividad antrópica (González, 2018; González et al., 2020). Por ello, el objetivo del trabajo es analizar los cambios en la vegetación ribereña asociados a formas y procesos geomorfológicos, entre los años 2009 y 2019, en la cuenca baja del arroyo Saladillo de García.

\section{MATERIALES Y MÉTODOS}

La investigación se basó en el reconocimiento y análisis visual de los cambios en la vegetación ribereña asociados a la dinámica geomorfológica fluvial en el área de estudio. Para esto se realizó un análisis visual multitemporal de imágenes satelitales de alta resolución espacial extraídas de Google Earth Pro ${ }^{\circledR}$ para los años 2009 y 2019 , previamente georreferenciadas. La elección de este intervalo temporal se fundamenta 
en que el período constituye el rango de años mínimo en el cual se pueden detectar cambios en la relación geomorfología y vegetación (Marston, 2010; Hupp, 2016).

Dentro del área de estudio se seleccionaron tres unidades de muestreo (UM), dos de ellas de aproximadamente $0,8 \mathrm{~km}^{2}$ y una $1 \mathrm{~km}^{2}$ (denominadas UM-I, UM-II y UM-III). Corresponden a sectores representativos del área donde se observaron intervenciones antrópicas en las formas fluviales y los mayores cambios en la distribución y cobertura de la vegetación. La elección de la escala se realizó teniendo en cuenta la propuesta de Hughes (1997) tomada por Sandercock et al. (2007) donde sostiene que en el estudio de la interrelación vegetación-geomorfología la relación es más nítida cuando se recurre a una micro-escala.

Se identificaron y diferenciaron tres tipos de coberturas del suelo: suelo descubierto, vegetación herbácea y vegetación arbustiva. Para el cálculo de las áreas de cada categoría se digitalizaron en el software ArcGIS ${ }^{\circledR}$ los polígonos correspondientes a cada cobertura (asumiendo las posibles distorsiones de área derivadas de la proyección utilizada por las imágenes de Google Earth Pro ${ }^{\circledR}$ ). Los datos de cada UM se representaron en gráficos y cartografía temática. Para determinar en términos espaciales como fue la variación de coberturas en ambos años se utilizó la herramienta Intersect del $\operatorname{ArcGIS}^{\circledR}$ a partir de la cual se superpusieron las capas correspondientes a las categorías de los años 2009 y 2019. Las áreas de cada intersección fueron resumidas en una matriz de cambios elaborada en Excel. El cruce de datos permitió ubicar con precisión las permanecías y variaciones de las coberturas entre los dos años considerados.

\section{ÁREA DE ESTUDIO}

La cuenca del arroyo Saladillo de García se localiza en el suroeste de la provincia de Buenos Aires (Argentina), nace en cercanías del sistema serrano de Ventania y desemboca en el estuario de Bahía Blanca (Figura 1). Su forma es alargada en sentido norte-sur y recorre un amplio valle caracterizado por una baja a muy baja pendiente general del terreno. Se encuentra latitudinalmente comprendida en la faja zonal de los climas templados de características continentales, con variaciones térmicas y pluviométricas marcadas a lo largo del año. Las temperaturas medias oscilan entre los $14^{\circ} \mathrm{C}$ y los $20^{\circ} \mathrm{C}$ y es característica de esta región la gran variabilidad de las precipitaciones, que es común en ambientes áridos o semiáridos (Campo de Ferreras, Capelli de Steffens, y Diez, 2004; Casado, 2013; Casado y Campo, 2019) (Figura 2). En este área, tanto el monto efectivo de las precipitaciones anuales como su distribución mensual exhiben una marcada variabilidad interanual con la ocurrencia de períodos extremadamente secos y húmedos (Scian, 2000; Casado y Campo, 2019; Ferrelli, Bohn, y Píccolo, 2012). En el año 2009 se registró un periodo de sequía en la región en el cual la precipitación anual fue de $350 \mathrm{~mm}$ siendo un valor muy inferior al valor medio para el período seleccionado $(605 \mathrm{~mm})$.

En el sector inferior de la cuenca, donde se localiza el área de estudio, la capacidad erosiva del agua se reduce debido a los gradientes de pendiente casi nulos, determinando formas fluviales poco definidas. Son característicos los cauces y canales angostos, muchos de ellos intermitentes y algunos con presencia de cubierta vegetal, y por presentar extensas llanuras de inundación. A diferencia de los cauces ocupados permanentemente por agua, que muestran regularidad en la distribución de la vegetación en el espacio y el tiempo, en los cauces efímeros característicos del área, la naturaleza irregular de los flujos determina efectos variables en los procesos 
geomorfológicos haciendo más o menos favorable las condiciones para la instalación de las distintas comunidades vegetales (González, 2018; González et al., 2020) .

Figura 1. Área de estudio (los recuadros UM-I, UM-II y UM-III corresponden a las Unidades de Muestreo consideradas en el trabajo) 


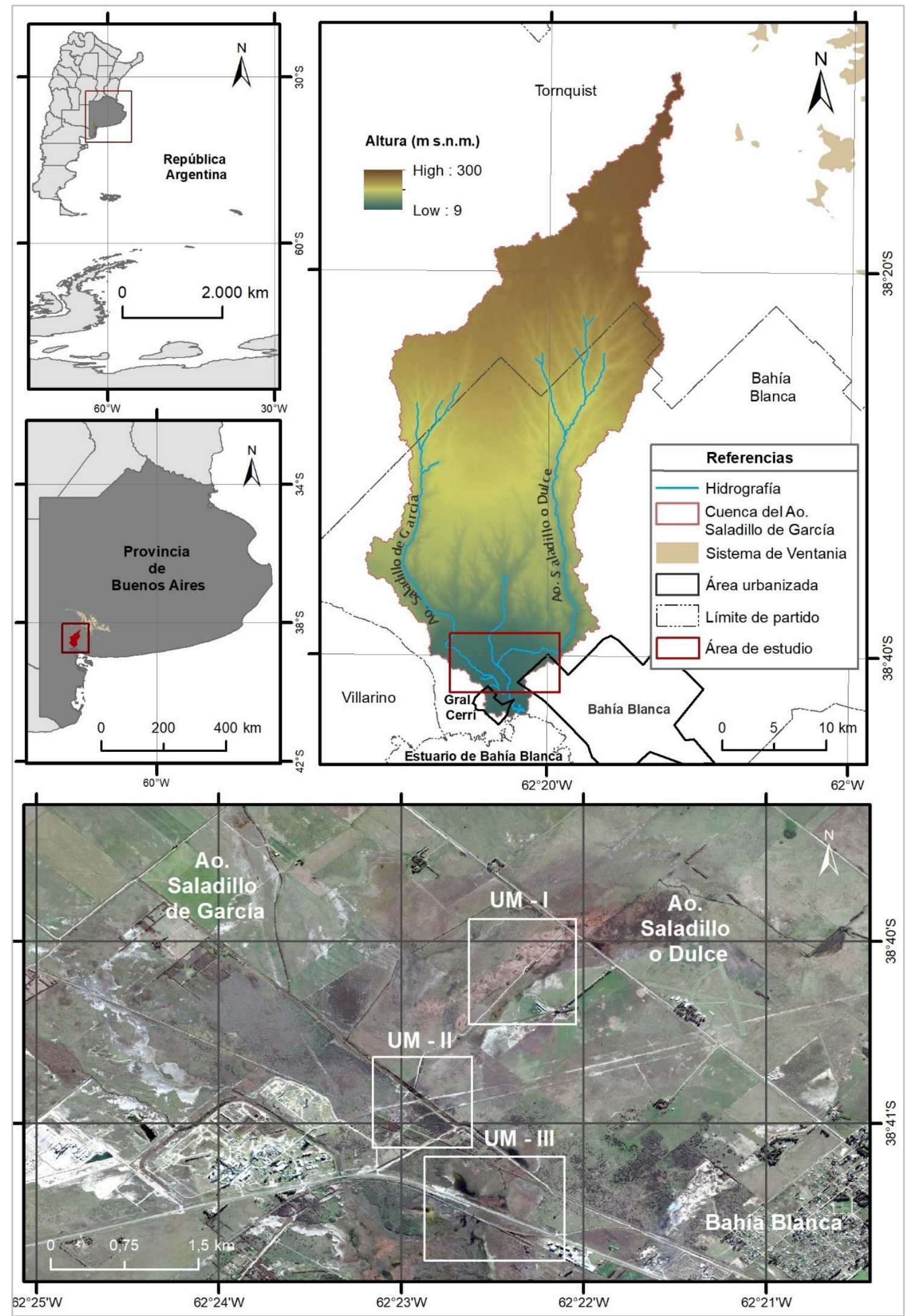

Fuente: SIG250 (IGN) - DEM SRTM - Google Earth Pro ${ }^{\circledR}$

Figura 2. Precipitación y temperatura media en Bahía Blanca para el período 20092019 


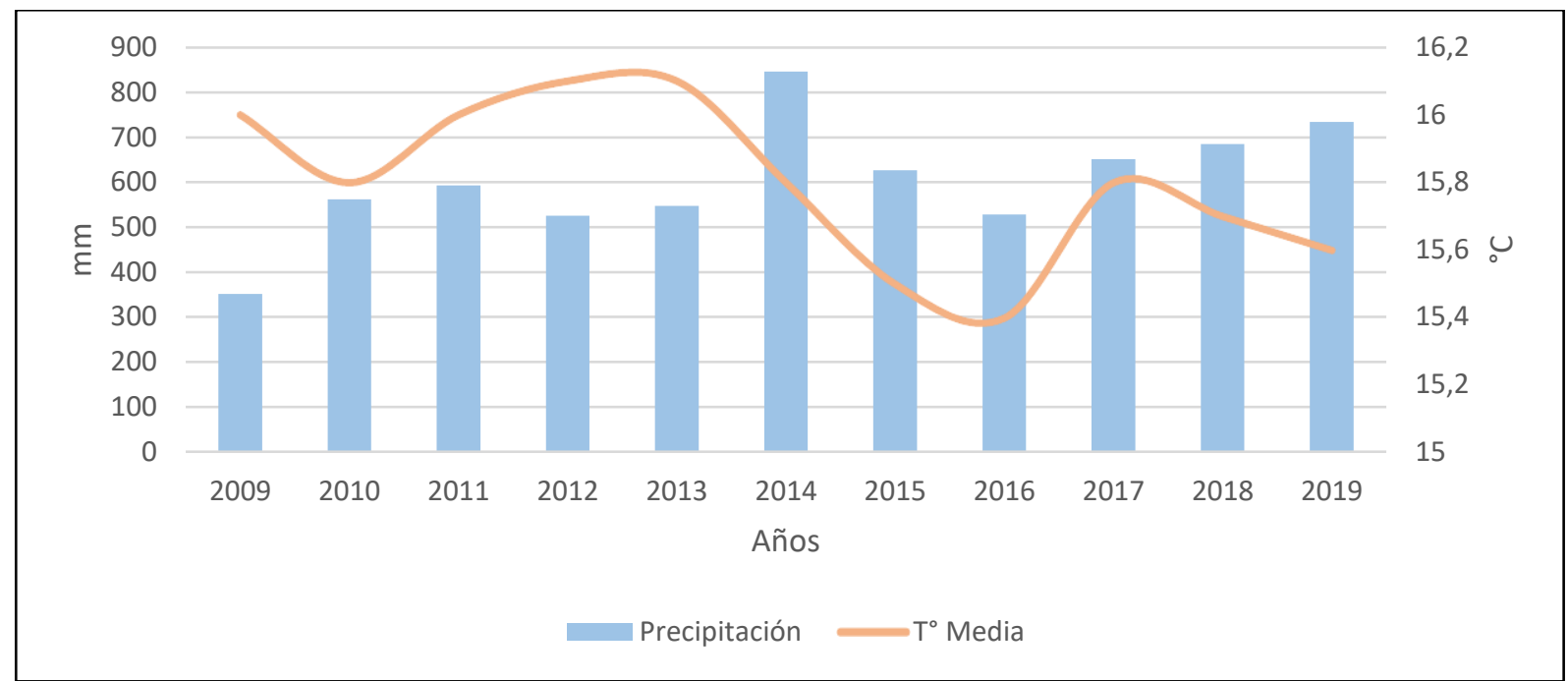

Fuente: Servicio Meteorológico Nacional (SMN) y Bolsa de Cereales y Productos de Bahía Blanca

El área constituye una zona de transición desde un ambiente salino, cercano a la desembocadura, con suelos arcillosos y poco permeables hacia el norte, donde se presentan suelos más ricos y favorables para la instalación y desarrollo de nuevas especies y asociaciones (Benedetti y Campo de Ferreras, 2006). Las plantas que habitan en el área tienen pocas exigencias y una gran aptitud ecologica. Si bien la cobertura vegetal natural se encuentra modificada prácticamente en su totalidad, no solo por las prácticas agrícolas y ganaderas sino también por la introducción de otras especies ajenas al entorno, en lugares donde permanece vegetación natural, ésta refleja la relación suelo-paisaje (Benedetti y Campo de Ferreras, 2006). Dominan en el área la estepa arbustiva halófila y matorrales halófilos integrados por arbustos ramosos, algunos con espinas, de uno a dos metros de altura. Las principales especies son: Cyclolepis genistoides, Atriplex undulata, Condallia microphila, Heterostachys ritteriana. También se encuentran especies de pajonales de Spartina, arbustales de Allenrolfea patagonica, estepas de Sarcocornia perennis, arbustales de Cyclolepis genistoides y Suaeda divaricata y sectores con pastizal halófilo (Verettoni, 1950; Nebbia y Zalba, 2007; Benedetti y Campo de Ferreras, 2006; Sanhueza et al., 2014) (Figura 3).

Figura 3. Situación de la vegetación en los márgenes fluviales del arroyo Saladillo de García: a-b) Tramos fluviales intervenidos; c-d-e) Especies halófilas: c. Sarcocornia perennis, d. Atriplex undulata, e. Suaeda divaricata 

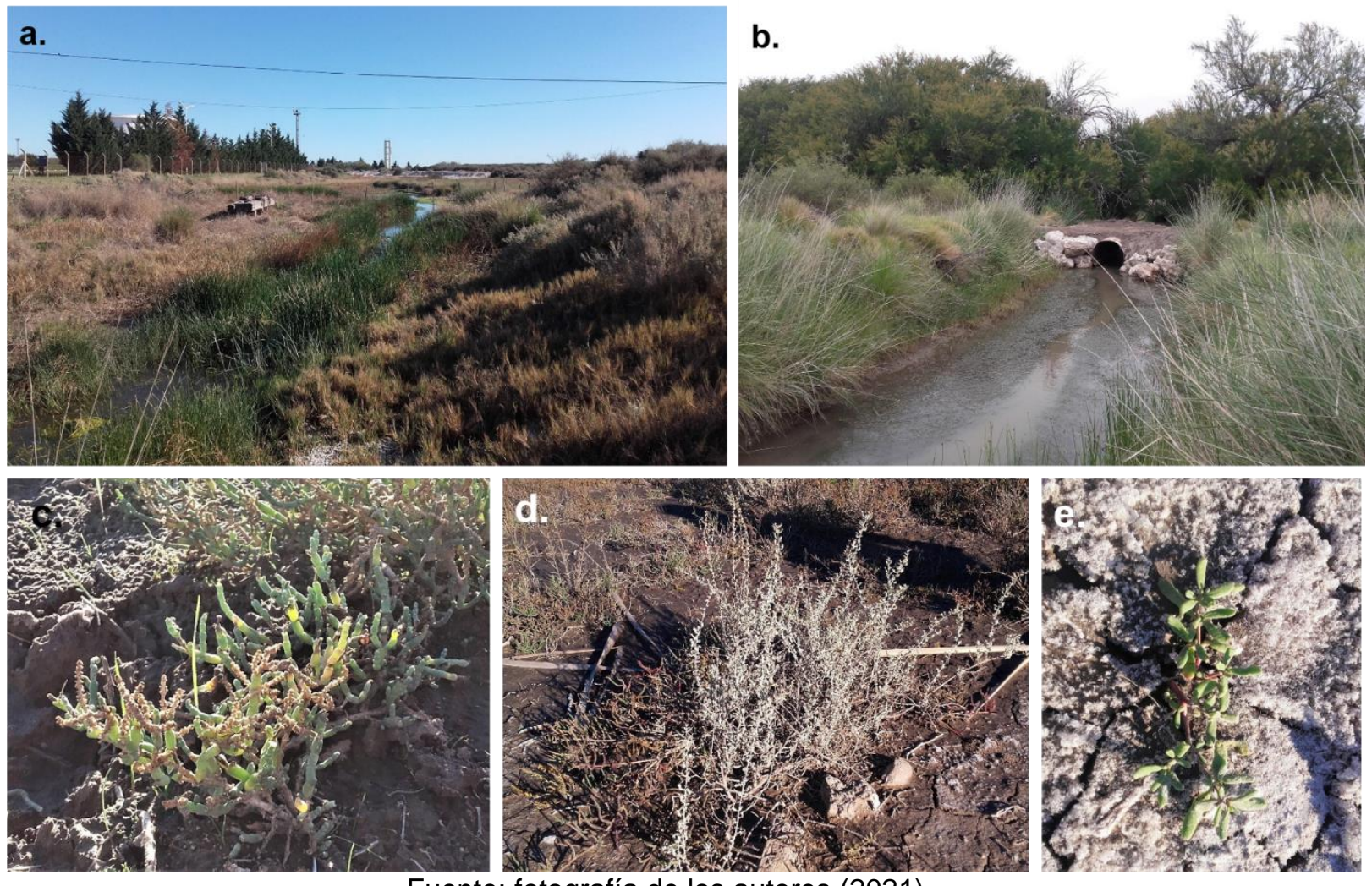

Fuente: fotografía de los autores (2021)

Respecto a los usos del suelo, actualmente el sector constituye una zona de interface entre el ambiente rural y el urbano que se caracteriza por presentar usos múltiples, donde se mezclan actividades de tipo hortícolas con usos industriales y residenciales. El creciente protagonismo que adquieren las sociedades en este espacio (Urriza, 1998; Lorda, 2005, 2006; Sereno, 2017), ha generado modificaciones en los equilibrios naturales, particularmente en la morfodinámica fluvial, que está siendo reemplazada por formas adaptadas a las necesidades de la sociedad, representando además un cambio en la composición y distribución de las comunidades vegetales que se adaptan a las nuevas formas y procesos fluviales.

\section{RESULTADOS Y DISCUSIÓN}

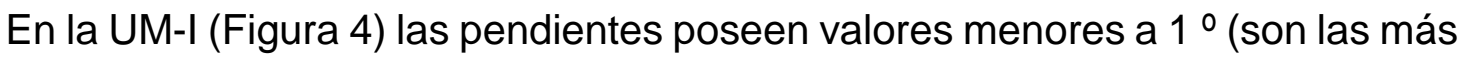
bajas del área); los cauces y canales en algunos tramos no están definidos ni poseen continuidad, por lo que el agua escurre de manera laminar produciéndose anegamientos temporales (González, 2018). Si se compara ambas fechas se observa que la morfología del cauce del arroyo existente en el año 2009 fue reemplazada por una canalización que se extiende desde la ruta nacional № 35 en forma recta a lo largo de $2 \mathrm{~km}$. Debido a esta intervención antrópica, el canal principal resigna su función de transporte de agua y sedimentos, en favor del canal artificial. Los canales intermitentes que bordean el curso principal quedan restringidos a pequeñas incisiones (surcos) en el terreno que colectan agua, pero no la transportan.

Con respecto a la vegetación, el cambio más significativo se identificó en la cantidad y distribución de cobertura arbustiva. En el año 2009 esta cobertura ocupaba $288 \mathrm{~m}^{2}$ y para el año 2019 el área ocupada era de sólo 132,2 m². En 2009, esta cobertura representaba más del $42 \%$ del total del área del muestreo y tenía una 
distribución uniforme y continúa concentrada mayormente en torno al curso principal, pero para el año 2019 la distribución se fragmenta y se restringe a la formación de "parches" de vegetación separados por suelo descubierto representando menos del $19 \%$ del área considerada.

Por otro lado, se observó un incremento respecto a la cobertura herbácea que avanzó en algunos sectores descubiertos de vegetación y áreas ocupadas por vegetación arbustiva. En el año 2009 la cobertura herbácea representaba poco más del $14 \%$ del total del área mientras que para el 2019 la misma representa casi el 25 $\%$ del área total de la UM-I. Con respecto al suelo descubierto, se observó un aumento de la superficie para el 2019 de $88,4 \mathrm{~m}^{2}$ respecto al 2009, lo que representa un aumento de $12,89 \%$ de superficie.

Figura 4. Distribución de las coberturas del suelo de un tramo del cauce del arroyo Saladillo o Dulce correspondiente a la UM-I.

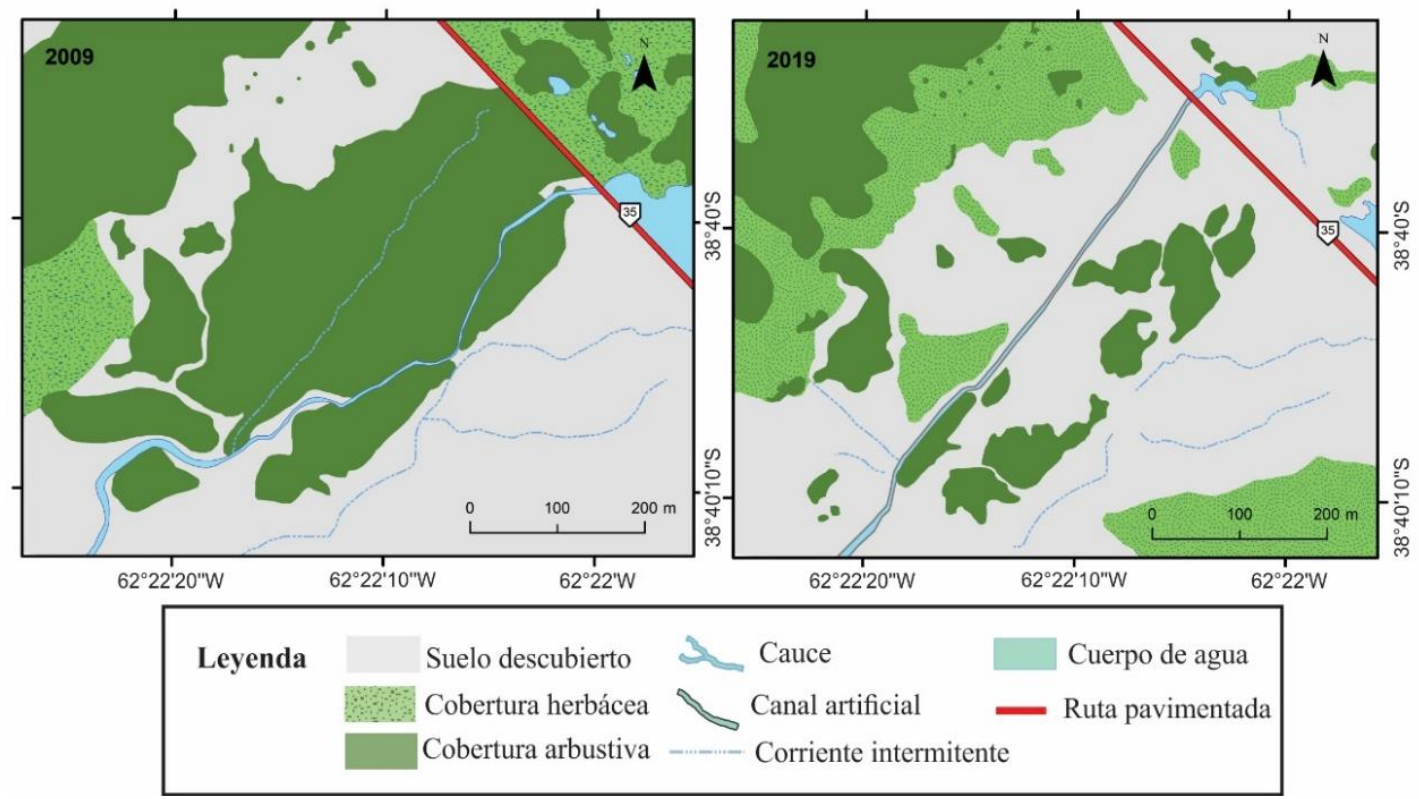

Variación porcentual de coberturas entre los años 2009-2019 en la UM-I

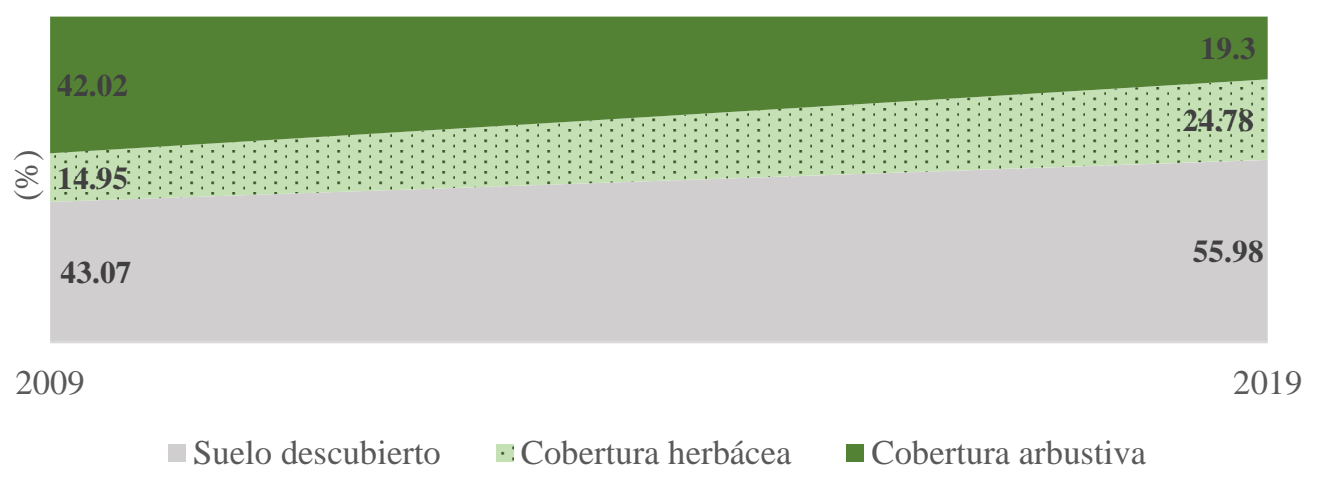

Fuente: elaboración propia sobre la base de imágenes de Google Earth Pro ${ }^{\circledR}$

La canalización del tramo identificado pudo ser uno de los motivos del cambio en el tipo y distribución de las coberturas ya que la incisión llevada a cabo, concentra el agua reduciendo la extensión de la superficie de la llanura de inundación y con esto su disponibilidad para la vegetación. En este caso, los patrones de vegetación son indicadores de cambio, ya que reflejan las diferencias de las condiciones de humedad 
en la llanura de inundación. Hardison et al. (2009) plantean esta identificación como el proceso de "secado de zonas ribereñas" como respuesta a la incisión de cauces, concepto al que denominaron "sequía riparia" comprobando en su análisis que el nivel freático de la llanura de inundación disminuye considerablemente luego de la canalización de un cauce. Este proceso, si bien es aplicado a una zona urbana, sus orígenes son similares y aplicables al área de estudio. Cabe destacar, sin embargo, que los autores mencionados realizan pruebas en aguas subterráneas y en el caso particular de esta investigación, es la vegetación el elemento que se tiene en cuenta como indicador del cambio. En este sentido, Sandercock et al. (2007) afirman que los desvíos de flujo, así como otras intervenciones antrópicas en los suministros de agua, provocan cambios en los regímenes de flujo de la superficie y del subsuelo e interrumpen los flujos de sedimentos y nutrientes, que a menudo resultan en cambios marcados en la vegetación. Respecto a la fragmentación y formación de "parches" de vegetación en el área, Levine y Stromberg (2001) sostienen que los cambios en la disponibilidad hídrica pueden inhibir el crecimiento y avance de las plantas y crear brechas en las comunidades ribereñas y en el futuro, estas áreas desocupadas forman áreas de colonización para plantas más oportunistas y tolerantes al estrés. Con el tiempo, esto puede conducir a generar cambios a gran escala en la estructura y composición de la vegetación ribereña local.

Con respecto a la UM-II (Figura 5) cabe destacar que, si bien durante el período de años seleccionado, no se identificaron cambios significativos en la geomorfología del área, fue seleccionada por estar localizada aguas abajo a la canalización identificada en la UM-I por lo que se considera que los cambios identificados en la distribución de la vegetación pueden estar vinculados a una acción antrópica indirecta vinculada a los cambios dados aguas arriba del sector. Se identificó una barrera antrópica (camino rural) dispuesta de forma transversal al cauce principal que actúa como nivel de base local y obliga a este a redireccionar su rumbo. Se originan geoformas acumulativas en el curso fluvial. Si bien la existencia del camino y el depósito sedimentario son previos a los años considerados, ambos se originan a partir de una acción antrópica directa que fomenta la inestabilidad de las formas fluviales y en consecuencia modifica la distribución de la vegetación del lugar. Esto sumado a la escasa pendiente local del terreno genera acumulaciones de agua cuyo tamaño es variable y pueden llegar hasta los $40 \mathrm{~m}^{2}$ de superficie en períodos húmedos. En momentos de excesos de precipitación, la carga sedimentaria arrastrada por el agua proveniente del canal se encuentra con un cambio importante en su dirección, lo que hace que el agua pierda capacidad de transporte y deposite el material sedimentario en esta zona (Figura 6-a-b). Cabe destacar que estas zonas de depositación del material si bien fueron identificadas en el terreno, no fueron representadas en la cartografía dada la escala de la misma.

Figura 5. Distribución de las coberturas del suelo en un tramo del cauce del arroyo Saladillo de García correspondiente a la UM-II 


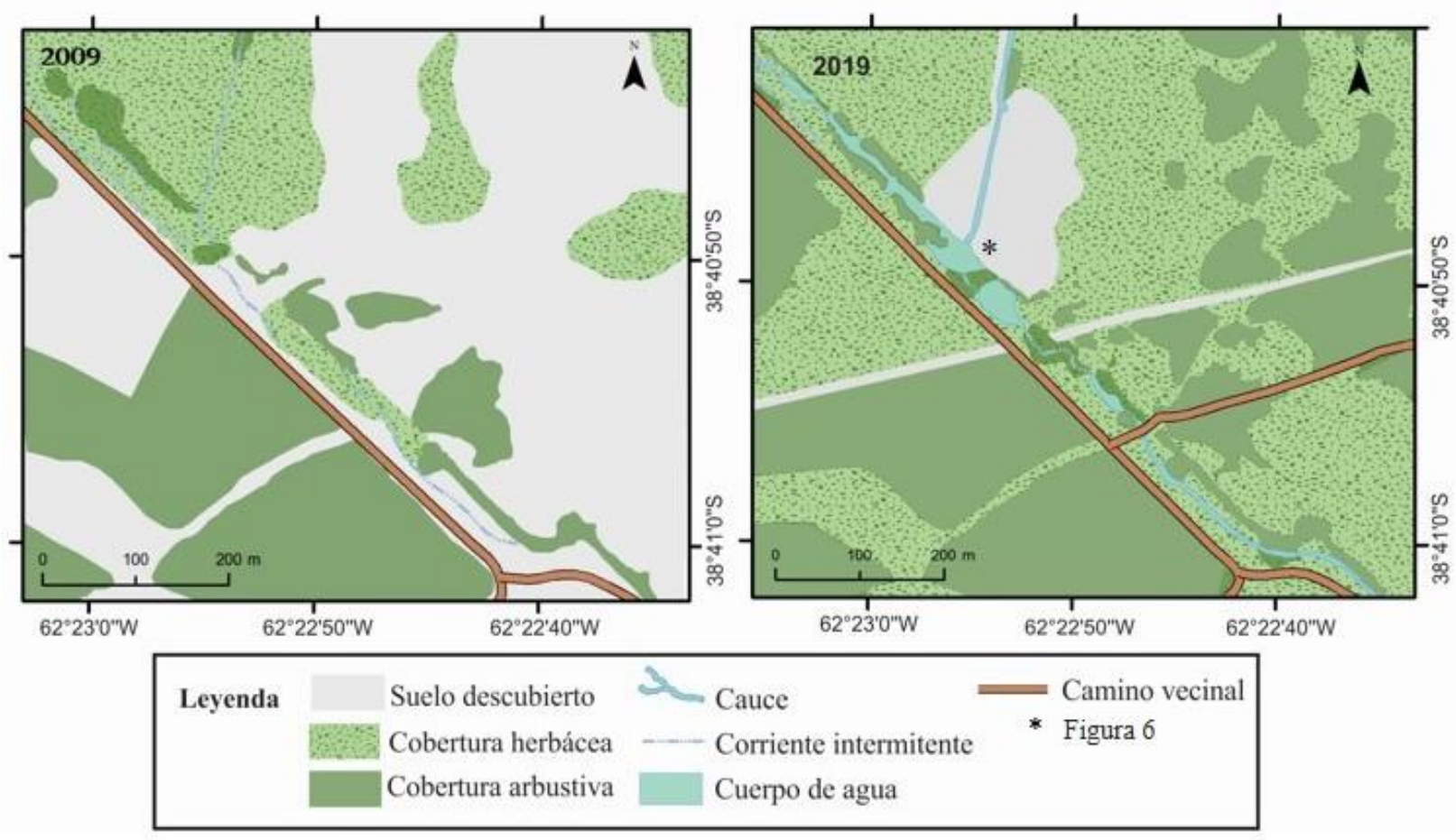

Variación porcentual de coberturas entre los años 2009-2019 en la UM-II

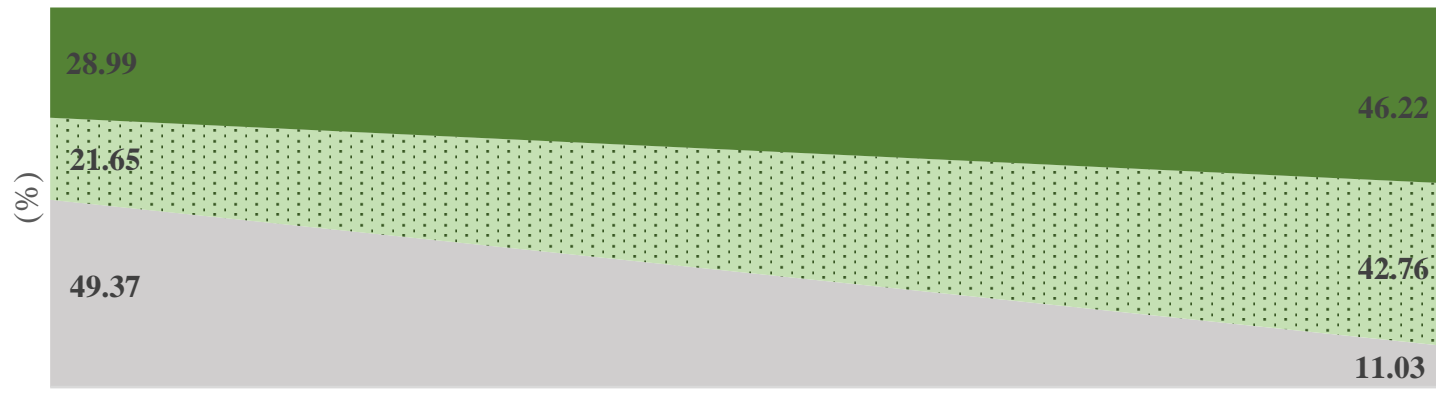

Fuente: elaboración propia sobre la base de imágenes de Google Earth Pro ${ }^{\circledR}$

En esa área en particular se generó un micro relieve propicio para dar inicio al proceso de sucesión vegetal alrededor de las lagunas, tal como fue observado por Benedetti y Campo de Ferreras (2006) para otros sectores del periurbano con las mismas características aquí mencionadas, para el paisaje de halófilas que bordea la zona de Bahía Blanca. En estas, la creación de cualquier nuevo hábitat atrae un conjunto de especies particularmente adaptadas para actuar como invasoras. En cuanto la salinidad disminuye, por el aumento en los aportes de agua dulce en este caso, aparecen nuevas especies y asociaciones entre ellas (Benedetti y Campo de Ferreras, 2006). Hupp, Dufour y Bornette (2016) consideran que la presencia de hábitats pioneros puede usarse como un indicador de la dinámica global del sistema y que esta información puede integrarse a lo largo del tiempo (décadas) para reconstruir cuantitativamente la trayectoria del paisaje fluvial y los cambios hidrológicos y morfológicos mediante el uso de imágenes y mapas antiguos.

En la figura 5 se observa lo expresado en el aumento de la cobertura arbustiva en los alrededores de estos los cuerpos de agua. Esto coincide a su vez con el estudio de 
Gumbricht, McCarthy y Bauer (2005) acerca de los procesos de agradación en humedales, en el cual demuestran la sensibilidad de la vegetación ante las pequeñas diferencias locales de elevación y además como la vegetación influye en el aumento de las tasas de agradación del sedimento. En consonancia con esto, Heppell et al. (2009) y más recientemente Hupp, Dufour y Bornette (2016) muestran que las estructuras de la vegetación inducen una variabilidad local muy significativa en las tasas de sedimentación y que el establecimiento inicial de esta vegetación aumenta la rugosidad hidráulica, facilitando una mayor sedimentación modificando las superficies iniciales relativamente inestables en superficies estables favorables para el reclutamiento de especies posteriores.

Figura 6. Ambientes fluviales de la UM-III: a) Acumulaciones sedimentarias (la flecha indica las primeras especies del proceso de sucesión vegetal), b) Acumulaciones sedimentarias recientes (no se observa aún presencia de vegetación).
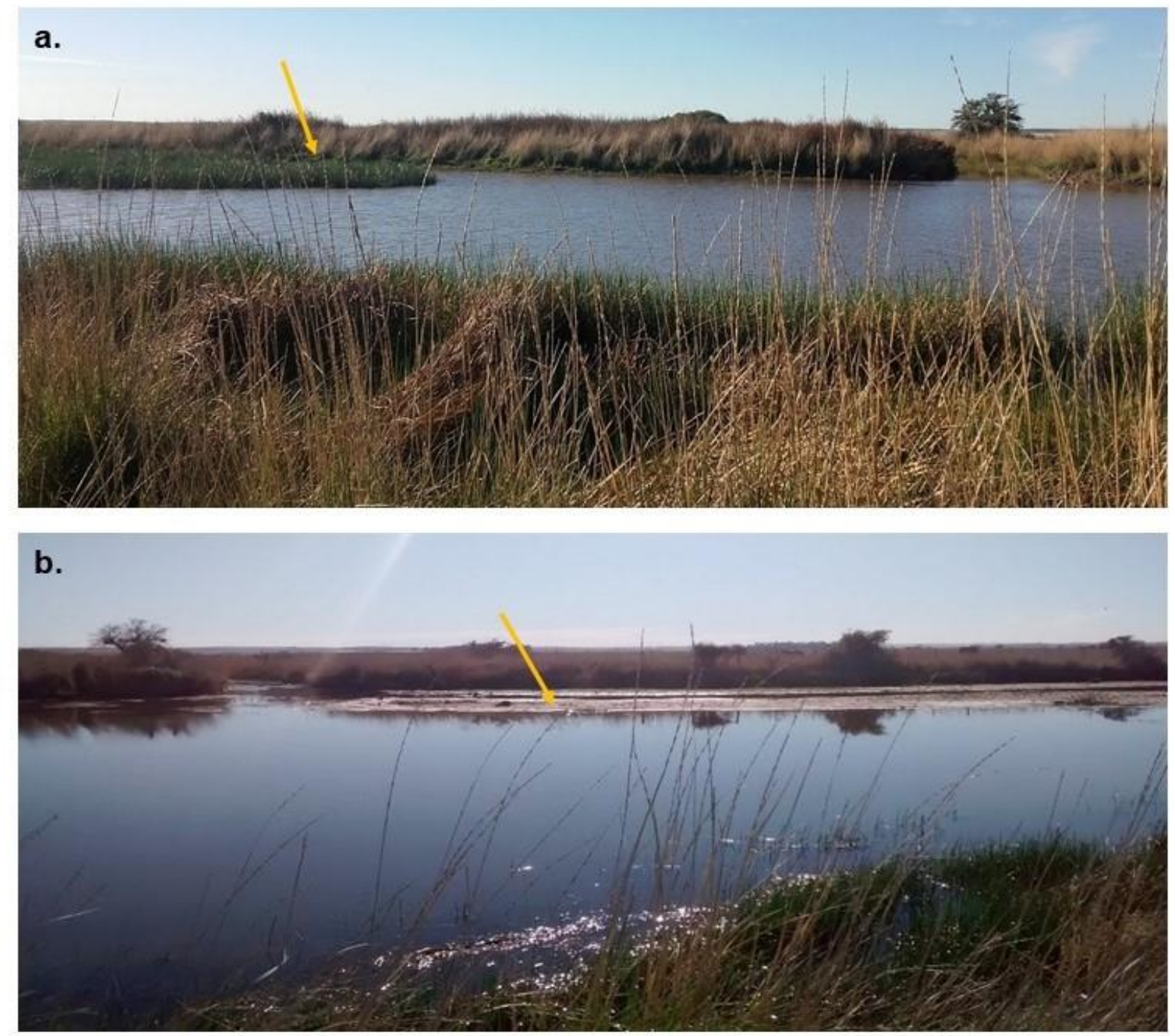

Fuente: fotografía de los autores (2021)

En la comparación de las coberturas vegetales de la UM-II se observó un aumento del área en ambas. La tendencia fue el avance de la vegetación herbácea en detrimento del suelo descubierto: la superficie de suelo desprovisto de vegetación se redujo de $49,4 \%$ a $11 \%$ mientras que, la superficie ocupada por la vegetación 
herbácea, aumentó su porcentaje de cobertura de 21,6 \% a 42,8 \% desde el 2009 al 2019 representando un incremento de poco más de $141 \mathrm{~m}^{2}$ de cobertura herbácea.

Con respecto a la cobertura arbustiva, se destaca el aumento del área ocupada por la misma en las márgenes del arroyo. Aquí, se podría inferir que la vegetación proporciona un componente de resistencia adicional en el sistema hidráulico del canal, lo cual es importante para reducir la erosividad del flujo y a su vez, este efecto de fricción conduce a un mayor potencial para que ocurra la sedimentación. Una mayor sedimentación reduciría la velocidad del flujo lo que podría con el tiempo repercutir en la morfología del canal debido a la depositación del sedimento y en consecuencia, contribuir a mejorar las condiciones para la colonización vegetal. Esta relación confirma el análisis realizado en el trabajo de Corenblit et al. (2011) en el cual observaron y corroboraron el efecto de la vegetación en la dinámica de los sedimentos y en la morfogénesis de distintas geoformas fluviales.

En la figura 7, se observa la distribución de las coberturas del suelo de la UMIII para los años 2009 y 2019. Esta unidad de muestreo es la que menor variación de coberturas presentó respecto a las dos unidades de muestreo anteriores.

Figura 7. Distribución de las coberturas del suelo de un tramo del cauce del arroyo Saladillo de García correspondiente a la UM-III

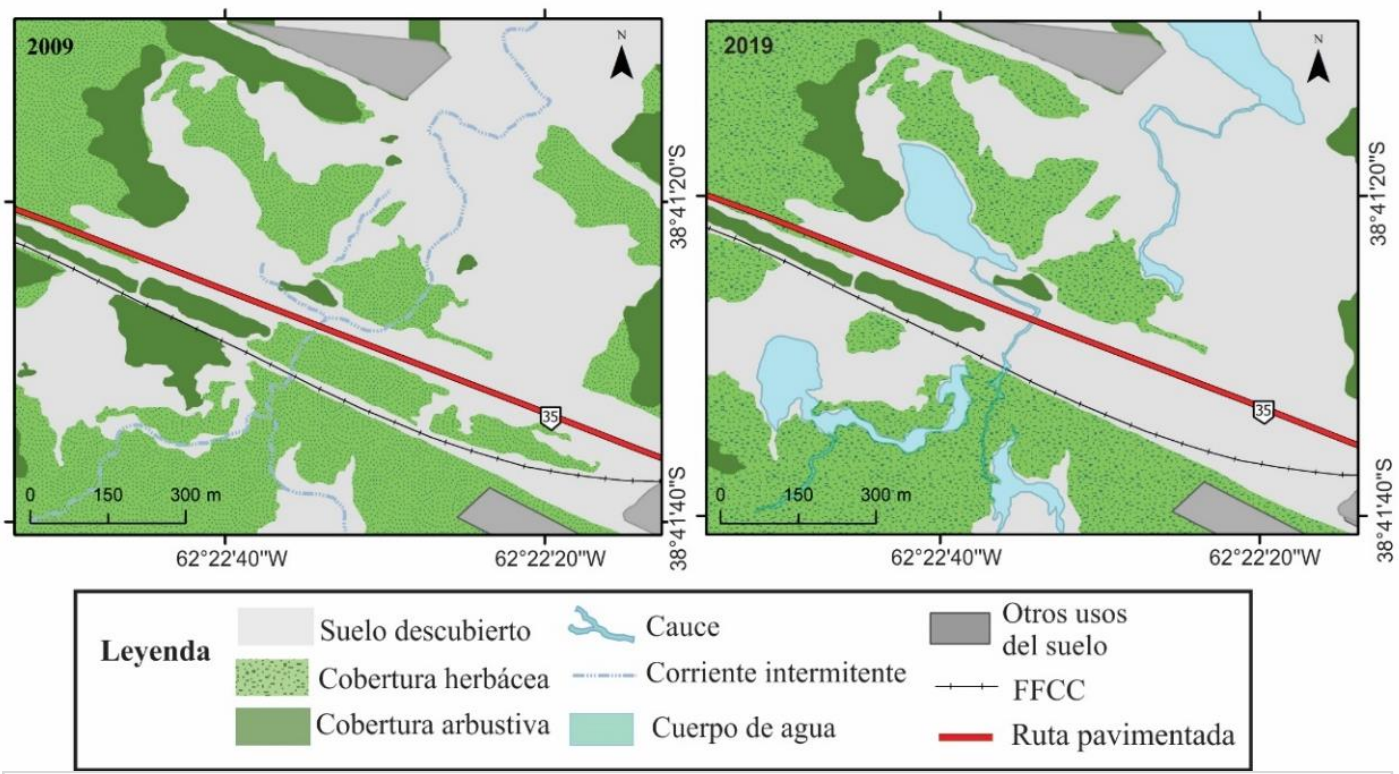

Variación porcentual de coberturas entre los años 2009-2019 en la UM-III

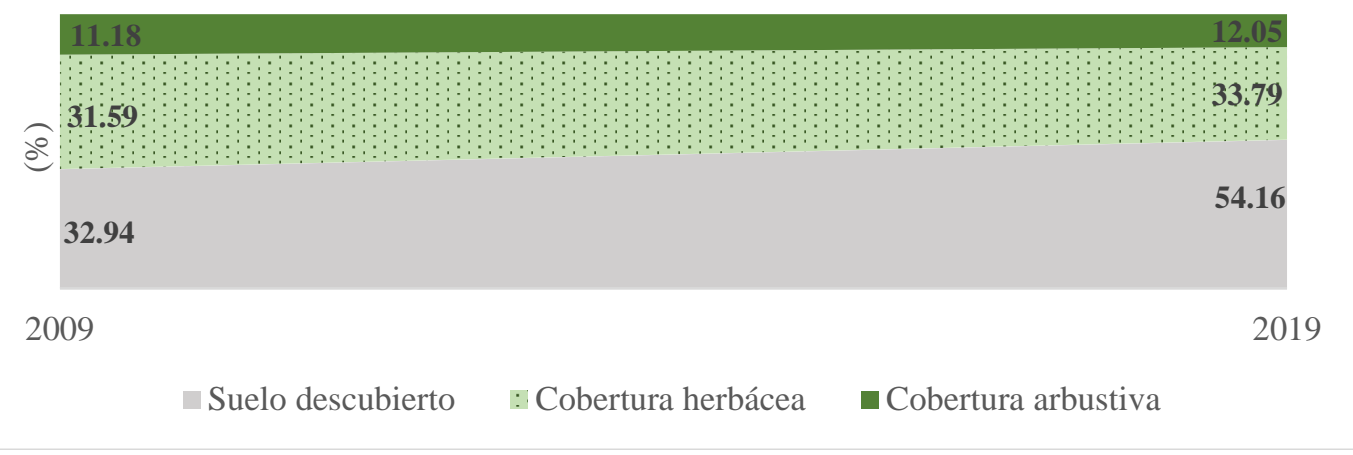

Fuente: elaboración propia sobre la base de imágenes de Google Earth Pro ${ }^{\circledR}$ 
En la figura 7, podemos observar o sector del tramo del arroyo fue seleccionado para la comparación porque en él no se identificaron cambios antrópicos directos 0 indirectos en la geomorfología entre un año y otro. Un hecho interesante a destacar en esta unidad de muestreo, es el aumento del área ocupada por cuerpos de agua en el 2019, reflejo de un período más húmedo que el del año 2009 (Casado y Campo, 2019). Debería esperarse entonces que la cantidad de vegetación aumente como consecuencia de una mayor disponibilidad de agua, sin embargo, se observó un aumento del suelo desprovisto de vegetación $(21 \%)$ y mientras que las coberturas vegetales se mantuvieron relativamente estables $(2,2 \%$ de aumento en la cobertura herbácea y $0,7 \%$ en la arbustiva). Esto puede tomarse como constatación de que los aumentos o disminuciones en la vegetación registrados en la UM-I y la UM-II no estuvieron asociados necesariamente a la disponibilidad hídrica del período húmedo del 2019 sino a las modificaciones en el curso fluvial aguas arriba del área, como se señaló anteriormente.

En la figura 8 se observa la distribución espacial de cambios de coberturas del suelo entre el año 2009 y 2019 (para facilitar la visualización las categorías que no registraron variación entre el 2009 y 2019, mantienen la simbología de las figuras 4, 5 y 7 -gris claro, verde claro y verde oscuro-). En términos generales, en la cartografía de cada unidad de muestreo se observa que la UM-I y la UM-II, tal como se planteó anteriormente, son las unidades de muestreo que mayor variación de superficie tuvieron en sus coberturas (aumentos o disminuciones). También se observa que en ambas unidades de muestreo se presentan las nueve categorías de cambios de coberturas.

En la UM-I se distingue en tamaño principalmente el polígono de intercambio entre cobertura arbustiva a suelo descubierto. Mientras que, en la UM-II, las categorías con mayor cantidad de $\mathrm{m}^{2}$ son las de suelo descubierto a cobertura herbácea y de suelo descubierto a cobertura arbustiva. En la UM-III, hay dos categorías de intercambio que no se presentan: el suelo descubierto a cobertura herbácea y cobertura herbácea a arbustiva. El resto de los cambios entre coberturas se presentan, pero las áreas son relativamente menores en $\mathrm{m}^{2}$ que las categorías de variación en la UM-I y UM-II. Por otra parte, al analizar las coberturas que se mantuvieron sin variación entre el 2009 y el 2019 (suelo descubierto-suelo descubierto, herbácea-herbácea y arbustiva-arbustiva), se comprueba que las mismas corresponden a los polígonos con mayor superficie. Esto permite reafirmar la idea de que los cambios más importantes en la distribución y forma de vida de la vegetación de las áreas consideradas para los muestreos fueron mayores en las unidades donde se reconoció que la actividad antrópica tuvo una relevancia significativa en las formas y procesos fluviales. En consonancia con el estudio realizado por Hupp y Osterkamp (1996) en los lugares donde la acción antrópica ha desequilibrado cursos o tramos de fluviales, la relación interdependiente entre la vegetación ribereña y la dinámica hidrogeomorfológica puede romperse. Sin embargo, durante los procesos de recuperación natural del sistema, la vegetación ribereña puede desempeñar un papel importante en el restablecimiento y reestructuración de las condiciones de equilibrio. 
Figura 8. Distribución espacial de las variaciones de cobertura entre los años 2009 y 2019
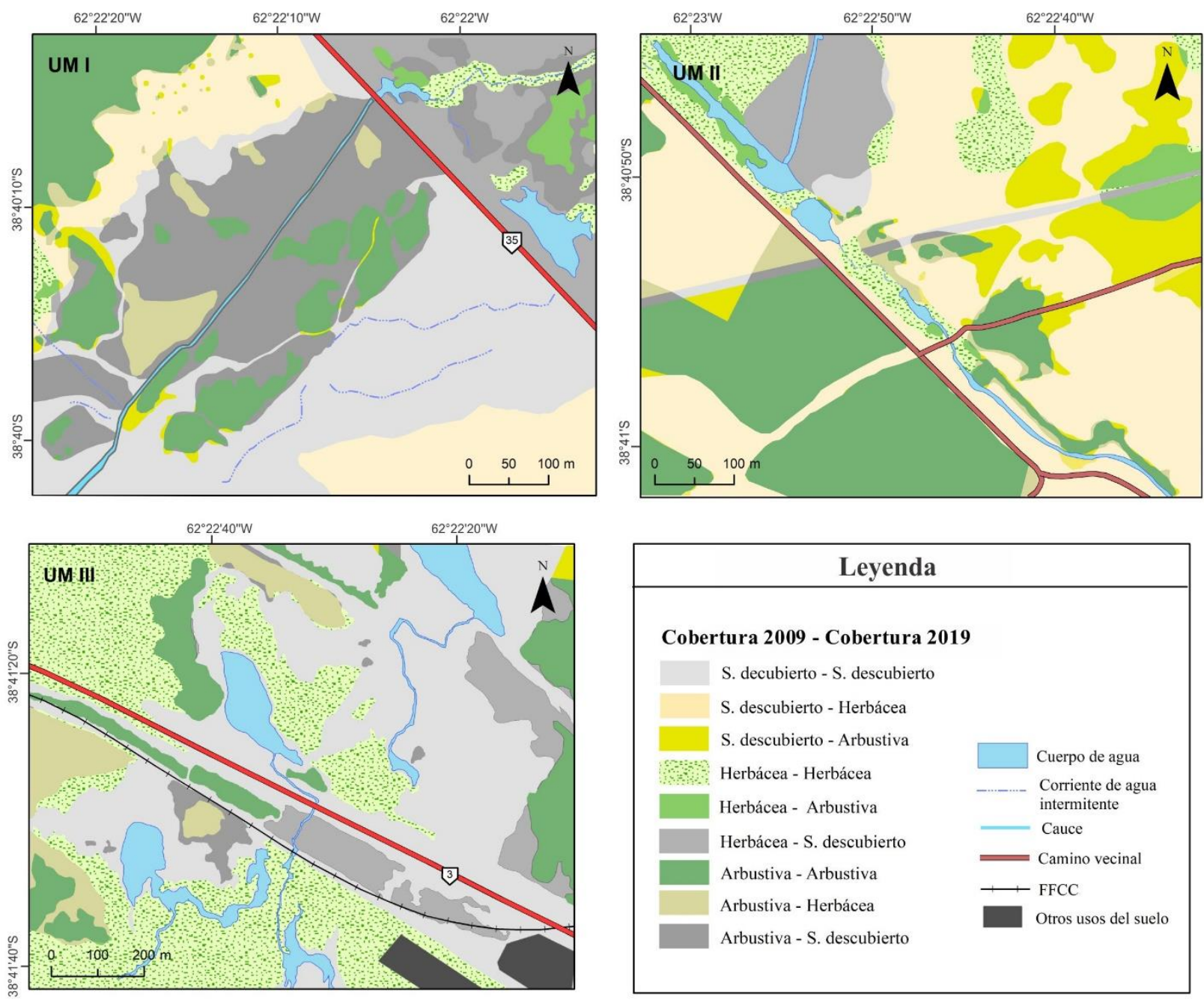

Fuente: elaboración propia

La figura 9 presenta la matriz de cambio de categorías entre ambos períodos. De este modo, por ejemplo, en la UM-I, de los $288 \mathrm{~m}^{2}$ de superficie que ocupaba la cobertura arbustiva en el 2009, para el año 2019, esta superficie se reduce a 132,2 $\mathrm{m}^{2}$ ya que, 39,5 $\mathrm{m}^{2}$ se convierten en cobertura herbácea y 130,6 $\mathrm{m}^{2}$ quedan desprovistos de vegetación (117,8 $\mathrm{m}^{2}$ permanecen con cobertura arbustiva). En la UMII la cobertura herbácea aumenta de $145 \mathrm{~m}^{2}$ a $286,7 \mathrm{~m}^{2}$ (aumento de $141,6 \mathrm{~m}^{2}$ ). Este avance se realiza sobre el suelo descubierto en su mayoría $\left(208,6 \mathrm{~m}^{2}\right)$ y en menor medida, sobre la cobertura arbustiva $\left(5,5 \mathrm{~m}^{2}\right)$. 
Figura 9. Matrices de cambio de cobertura entre los años 2009 y 2019 para UM-I, UM-II y UM-III

\begin{tabular}{|c|c|c|c|c|c|c|c|c|}
\hline \multirow{3}{*}{$\begin{array}{c}\text { UM-I } \\
\text { t1 : } 2009\end{array}$} & \multicolumn{8}{|c|}{ t2: 2019} \\
\hline & \multicolumn{2}{|c|}{$\begin{array}{l}\text { Cobertura } \\
\text { arbustiva }\end{array}$} & \multicolumn{2}{|c|}{$\begin{array}{l}\text { Cobertura } \\
\text { herbácea }\end{array}$} & \multicolumn{2}{|c|}{$\begin{array}{c}\text { Suelo } \\
\text { descubierto }\end{array}$} & \multicolumn{2}{|c|}{ Total 2009} \\
\hline & $\mathrm{m}^{2}$ & $\%$ & $\mathrm{~m}^{2}$ & $\%$ & $\mathrm{~m}^{2}$ & $\%$ & $\mathrm{~m}^{2}$ & $\%$ \\
\hline $\begin{array}{l}\text { Cobertura } \\
\text { arbustiva }\end{array}$ & 117,8 & 17,19 & 39,5 & 5,77 & 130,6 & 19,06 & 288 & 42,01 \\
\hline $\begin{array}{l}\text { Cobertura } \\
\text { herbácea }\end{array}$ & 8 & 1,17 & 10,1 & 1,47 & 84,3 & 12,30 & 102,4 & 14,94 \\
\hline $\begin{array}{c}\text { Suelo } \\
\text { descubierto }\end{array}$ & 6,4 & 0,93 & 120,2 & 17,53 & 168,5 & 24,59 & 295,1 & 43,05 \\
\hline Total 2019 & 132,2 & 19,29 & 169,8 & 24,77 & 383,5 & 55,94 & 685,4 & 100 \\
\hline
\end{tabular}

\begin{tabular}{|c|c|c|c|c|c|c|c|c|}
\hline \multirow{3}{*}{$\begin{array}{c}\text { UM-II } \\
\text { t1: } 2009\end{array}$} & \multicolumn{8}{|c|}{ t2: 2019} \\
\hline & \multicolumn{2}{|c|}{$\begin{array}{l}\text { Cobertura } \\
\text { arbustiva }\end{array}$} & \multicolumn{2}{|c|}{$\begin{array}{l}\text { Cobertura } \\
\text { herbácea }\end{array}$} & \multicolumn{2}{|c|}{$\begin{array}{c}\text { Suelo } \\
\text { descubierto }\end{array}$} & \multicolumn{2}{|c|}{ Total 2009} \\
\hline & $\mathrm{m}^{2}$ & $\%$ & $\mathrm{~m}^{2}$ & $\%$ & $\mathbf{m}^{2}$ & $\%$ & $\mathrm{~m}^{2}$ & $\%$ \\
\hline $\begin{array}{l}\text { Cobertura } \\
\text { arbustiva }\end{array}$ & 148,80 & 22,19 & 5,58 & 0,83 & 39,98 & 28,99 & 194,37 & 28,99 \\
\hline $\begin{array}{l}\text { Cobertura } \\
\text { herbácea }\end{array}$ & 45,30 & 6,76 & 72,47 & 10,81 & 27,37 & 21,65 & 145,14 & 21,65 \\
\hline $\begin{array}{c}\text { Suelo } \\
\text { descubierto }\end{array}$ & 115,79 & 17,27 & 208,65 & 31,12 & 6,59 & 0,98 & 331,03 & 49,37 \\
\hline Total 2019 & 309,90 & 46,22 & 286,70 & 42,76 & 73,95 & 11,03 & 670,55 & 100 \\
\hline
\end{tabular}

\begin{tabular}{|c|c|c|c|c|c|c|c|c|}
\hline \multirow{3}{*}{$\begin{array}{c}\text { UM-III } \\
\text { t1: } 2009\end{array}$} & \multicolumn{8}{|c|}{ t2: 2019} \\
\hline & \multicolumn{2}{|c|}{$\begin{array}{l}\text { Cobertura } \\
\text { arbustiva }\end{array}$} & \multicolumn{2}{|c|}{$\begin{array}{l}\text { Cobertura } \\
\text { herbácea }\end{array}$} & \multicolumn{2}{|c|}{$\begin{array}{c}\text { Suelo } \\
\text { descubierto }\end{array}$} & \multicolumn{2}{|c|}{ Total 2009} \\
\hline & $\mathrm{m}^{2}$ & $\%$ & $\mathrm{~m}^{2}$ & $\%$ & $\mathbf{m}^{2}$ & $\%$ & $\mathrm{~m}^{2}$ & $\%$ \\
\hline $\begin{array}{l}\text { Cobertura } \\
\text { arbustiva }\end{array}$ & 199,27 & 11,18 & 122,52 & 6,87 & 310,47 & 17,42 & 632,27 & 35,47 \\
\hline $\begin{array}{l}\text { Cobertura } \\
\text { herbácea }\end{array}$ & 0 & 0 & 479,74 & 26,92 & 83,27 & 32,07 & 563,02 & 31,59 \\
\hline $\begin{array}{c}\text { Suelo } \\
\text { descubierto }\end{array}$ & 15,45 & 0,87 & 0 & 0 & 571,62 & 32,07 & 587,07 & 32,94 \\
\hline Total 2019 & 214,71 & 12,05 & 602,27 & 33,79 & 965,37 & 54,16 & 1782,36 & 100 \\
\hline
\end{tabular}

En ambos recursos, la cartografía y las matrices, queda representada la distinción entre las UM-I y UM-II con respecto a la UM-III en lo referente a la relación geomorfología-vegetación ya que, esta última, como se mencionó con anterioridad, es la unidad de muestreo en la que menor intervención antrópica se identificó. Esta relación queda plasmada en los porcentajes de permanencia de las coberturas en la matriz de la UM-III respecto a los porcentajes de variación de coberturas en las dos primeras matrices. 


\section{CONCLUSIÓN}

En este estudio se constató la relación recíproca entre la tipología y distribución de la vegetación y las geoformas fluviales. Se comprobó que, si bien las variaciones en los patrones de vegetación ribereña, tanto en el tipo de cobertura como en su distribución, pudieron estar relacionados con las discontinuidades producto de la irregularidad de las precipitaciones, los cambios más significativos estuvieron asociados a las intervenciones antrópicas en los cursos fluviales. Estas intervenciones, que tuvieron efectos directos e indirectos en los procesos y la dinámica fluvial de las áreas aguas arriba y debajo, también repercutieron en la distribución y tipología de la vegetación.

Se observó que en la UM-I la canalización del cauce influyó en la disponibilidad de agua para la vegetación ribereña lo que generó la fuerte reducción de la vegetación en el área. En la UM-II, el análisis a escala local permitió observar la formación de micro relieves que dieron lugar a la instalación y crecimiento de plantas dando origen al inicio de la sucesión vegetal y a su vez, estas constituyeron un elemento que favoreció la retención de sedimentos y consecuente generación y crecimiento de geoformas mayores. La UM-III es la unidad donde no se registraron intervenciones antrópicas directas en las geoformas fluviales. Esto pone en evidencia que fueron los sectores donde se observaron intervenciones directas en los procesos fluviales los que presentaron mayor variación en la distribución y cobertura de la vegetación ribereña del área (aumentos o disminuciones) y a su vez, la vegetación fue el indicador de campo para la interpretación de dichos cambios.

El análisis de estas relaciones constituye un aporte al estudio integrado de una cuenca hidrográfica desde una perspectiva biogeomorfológica cuya aplicación puede ser extrapolada a otras cuencas de características similares como una herramienta en la interpretación y predicción de tendencias en la forma y procesos geomorfológicos fluviales. En ambientes fluviales intervenidos antrópicamente, comprender esta relación puede ser la clave para el re-establecimiento de las condiciones de equilibrio del sistema fluvial y una herramienta para la gestión de los excesos hídricos (inundaciones y anegamientos) característicos de estas áreas con bajo gradiente en sus pendientes.

\section{REFERENCIAS BIBLIOGRÁFICAS}

AUBLE, G. T., FRIEDMAN, J. M., y SCOTT, M. L. Relating riparian vegetation to present and future streamflows. Ecological Society of America, v.4, n.3, p. 544-554, 2015.

BANIYA, M. B., ASAEDA, T., FUJINO, T., JAYASANKA, S. M., MUHETAER, G., y LI, J. Mechanism of Riparian Vegetation Growth and Sediment Transport Interaction in Floodplain: A Dynamic Riparian Vegetation Model (DRIPVEM) Approach. Water, v.12, n.1, p. $77,2020$.

BEATO BERGUA, S., MARINO ALFONSO, J. L., POBLete PIEDRABUENA, M. Á., CUNILL ARTIGAS, R., y RODRÍGUEZ BERDASCO, J. M. Los pastos de montaña de la Sierra del Aramo (Macizo Central Asturiano): análisis geoecológico, evolución histórica y dinámica reciente. Documents d'anàlisi geogràfica, v.67, n.1, p. 5-32, 2021. 
BENEDETTI, G. M., y CAMPO DE FERRERAS, A. M. Paisaje de Halófilas en la bahía Blanca. In E. Mazzoni y M. Vazquez (Eds.), VI Jornadas Nacionales de Geografía Física, p. 130-135, 2006.

BROOKES, C. J., HOOKE, J. M., y MANT, J. Modelling vegetation interactions with channel flow in river valleys of the Mediterranean region. Catena, v.40, n.1, p. 93-118, 2000 .

CABRERA- AMAYA, D. y RIVERA-DÍAZ, O. Composición florística y estructura de los bosques ribereños de la cuenca baja del río Pauto, Casanare, Colombia. Caldasia, v.38, n.1, p. 53-85, 2016.

CABRERA- AMAYA, D., GIRALDO-KALIL, L. J., RIVERA-DÍAZ, O., y CASTRO-LIMA, F. Riqueza, composición y distribución de las plantas vasculares en sabanas y bosques ribereños de la cuenca baja del río Pauto (Casanare-Colombia). Revista de la Academia Colombiana de Ciencias Exactas, Físicas y Naturales, v.44, n.173, p.1018-1032, 2020.

CAMPO DE FERRERAS, A. M., CAPELLI DE STEFFENS, A., y DIEZ, P. G. El clima del Suroeste bonaerense (Ediuns), 2004.

CASADO, A. Human impacts and fluvial metamorphosis : the effects of flow regulation on the hydrology, morphology and water temperature of the Sauce Grande River, Argentina. Tesis Doctoral. Universidad Nacional del Sur, Bahia Blanca, 2013.

CASADO, A., y CAMPO, A. M. Extremos hidroclimáticos y recursos hídricos: estado de conocimiento en el suroeste bonaerense, Argentina. Cuadernos Geograficos, v.22, v.1-2, p.6-26, 2019.

CORENBLIT, D., STEIGER, J., GURNELL, A.M., TABACCHI, E. y ROQUES, L. Control of sediment dynamics by vegetation as a key function driving biogeomorphic succession within fluvial corridors. Earth Surface Processes and Landforms, v.34, n.13, p.1790-1810, 2009.

CORENBLIT, D., BAAS, A.C.W, BORNETTE, G., DARROZES, J., DELMOTTE, S., FRANCIS, R.A., GURNELL, A.M., JULIEN, F., NAIMAN. R.J. y STEIGER, J. Feedbacks between geomorphology and biota controlling Earth surface processes and landforms: a review of foundation concepts and current understandings. EarthScience Reviews, v.106, n.3-4, p.307-331, 2011.

DUARTE, S. D., y DE SOUSA LOPES, J. L. Gestão territorial e zoneamento ambiental na Bacia Hidrográfica do Rio Coruripe-AL: embates territoriais e perspectivas geográficas. Diversitas Journal, v.6, n.1, p. 957-975, 2021.

FERRELLI, F., BOHN, V. y., Y PICCOLO, M. C. Variabilidad de la precipitación y ocurrencia de eventos secos en el sur de la provincia de Buenos Aires (Argentina). Actas de Las IX Jornadas Nacionales de Geografía Física, p.15-28, 2012.

FLORES, D. G., SUVIRES, G., y DALMASSO, A. Distribución de la vegetación nativa en ambientes geomorfológicos cuaternarios del Monte Árido Central de Argentina. 
Revista Mexicana de Biodiversidad, v.86, n.1, p. 72-79, 2015.

GIORGIS, M. A., CINGOLANI, A. M., y CABIDO, M. R. El efecto del fuego y las características topográficas sobre la vegetación y las propiedades del suelo en la zona de transición entre bosques y pastizales de las sierras de Córdoba, Argentina. Boletín de La Sociedad Argentina de Botánica, v.48, n.3-4, p.493-513, 2013.

GONZÁLEZ, E., SHAFROTH, P. B., LEE, S. R., OSTOJA, S. M., y BROOKS, M. L. Combined effects of biological control of an invasive shrub and fluvial processes on riparian vegetation dynamics. Biological Invasions, v. 22, n.7, p. 2339-2356, 2020.

GONZÁLEZ, M. A. Hidrogeomorfología de la cuenca del arroyo Saladillo de García aplicada al ordenamiento del periurbano de Bahía Blanca. Universidad Nacional del Sur. Tesis de Grado. Universidad Nacional del Sur, Bahia Blanca. 2018.

GONZÁLEZ, M. A., GENTILI, J. O., y GIL, V. Cambios en la red hidrográfica en un sector del periurbano noroeste y oeste de Bahía Blanca debido a la influencia urbana. Revista Geográfica Digital, v.17, n.33, p.17, 2020.

GUITIÁN, M. R., VÁZQUEZ, J. A., y SAÑUDO, Í. P. Revisión del encuadre biogeográfico del Parque Natural do Invernadeiro (Ourense, Galicia) a partir de nuevos datos sobre su cubierta vegetal. Recursos rurais: revista oficial do Instituto de Biodiversidade Agraria e Desenvolvemento Rural (IBADER), v.16, p. 11-47, 2020.

GUMBRICHT, T., MCCARTHY, T. y BAUER, P. The micro-topography of the wetlands of the Okavango Delta, Botswana. Earth Surface Processes and Landforms, v. 30, n.1, p.27-39, 2005.

HAN, M. y BRIERLEY, G. Channel geomorphology and riparian vegetation interactions along four anabranching reaches of the Upper Yellow River. Progress in Physical Geography: Earth and Environment, v. 44, n.6, p. 898-922, 2020.

HARDISON, E. C., O'DRISCOLL, M. A., DELOATCH, J. P., HOWARD, R. J., y BRINSON, M. M. Urban Land Use, Channel Incision, and Water Table Decline Along Coastal Plain Streams, North Carolina 1. JAWRA Journal of the American Water Resources Association, v.45, n.4, p.1032-1046, 2019.

HEPPELL, C.M., WHARTON, G., COTTON, J.A.C., BASS, J.A.B. y ROBERTS, S.E.. Sediment storage in the shallow hyporheic of lowland vegetated river reaches. Hydrological Processes, v. 23, p. 2239- 225, 2009.

HUGHES, F. M. R. Floodplain biogeomorphology. Progress in Physical Geography, v. 21, n.4, p. 501-529, 1997.

HUPP, C.R. y OSTERKAMP, W.R. Riparian vegetation and fluvial geomorphic processes. Geomorphology, v.14, n.4, p. 277-295, 1996.

HUPP, C. R. Riparian vegetation recovery patterns following stream channelization: a geomorphic perspective. Ecology, v.73, n.4, p.1209-1226, 2016. 
HUPP, C.R., DUFOUR, S. y BORNETTE, G. Vegetation as a tool in the interpretation of fluvial geomorphic processes and landforms in humid temperate areas. In Tools in Fluvial Geomorphology, Kondolf M, Piégay H (eds). John Wiley \& Sons: Chichester, 2016.

ISTANBULLUOGLU, E., y BRAS, R. L. Vegetation-modulated landscape evolution: Effects of vegetation on landscape processes, drainage density, and topography. Journal of geophysical research, v.110, p.1-19, 2005.

JERIN, T. Scale associated coupling between channel morphology and riparian vegetation in a bedrock-controlled stream. Geomorphology, v.375, p.107- 562, 2021.

LEVINE, C. M., y STROMBERG, J. C. Effects of flooding on native and exotic plant seedlings: Implications for restoring south-western riparian forests by manipulating water and sediment flows. Journal of Arid Environments, v.49, n.1, p.111-131, 2001.

LORDA, M. A. El desarrollo local, estrategia de gestión ambiental de la actividad agrícola en espacios próximos a la ciudad de Bahía Blanca. Tesis Doctoral. Universidad Nacional del Sur, Bahia Blanca, 2005.

LORDA, M. A. El desarrollo local, estrategia de gestión ambiental de la actividad agrícola en espacios próximos a la ciudad de Bahía Blanca. Revista Universitaria de Geografía, v. 15, p.15-26, 2006.

MARSTON, R. A. Geomorphology and vegetation on hillslopes: Interactions, dependencies, and feedback loops. Geomorphology, v.116, n.3-4, p.206-217, 2010.

MASSOLO, L. Introducción a las herramientas de gestión ambiental. Series: Libros de Cátedra. Editorial de la Universidad Nacional de La Plata (EDULP), 195 p, 2015.

MAZZOLA, M. B., KIN, A. G., MORICI, E. F., BABINEC, F. J., y TAMBORINI, G. Efecto del gradiente altitudinal sobre la vegetación de las sierras de Lihue Calel (La Pampa, Argentina). Bioletin de La Sociedad Argentina de Botánica, v.48, n.1 y 2, p.103119, 2008.

MUÑOZ-PEDREROS, A. La evaluación del paisaje: una herramienta de gestión ambiental. Revista Chilena de Historia Natural, v.77, n.1, p.139-156, 2004.

NALLAPERUMA, B., y ASAEDA, T. The long-term legacy of riparian vegetation in a hydrogeomorphologically remodelled fluvial setting. River Research and Applications, v.36, n.8, p.1690-1700, 2020.

NEBBIA, A. J., y ZALBA, S. M. Comunidades Halófilas de la costa de la Bahía Blanca (Argentina): Caracterización, mapeo y cambios durante los últimos cincuenta años. Boletín de La Sociedad Argentina de Botánica, v.42, n.3-4, p.261-271, 2007.

O'DONNELL, J., FRYIRS, K., y LEISHMAN, M. R. Can the Regeneration of Vegetation from Riparian Seed Banks Support Biogeomorphic Succession and the Geomorphic 
Recovery of Degraded River Channels? River Research and Applications, v.31, n.7, p.834-846, 2015.

OlLeRo, A., IBISATE, A., ACÍN, V., DÍAZ, E., GRANADO, D., y HORACIO, J. Innovación y libertad fluvial. En VII Congreso lbérico sobre Gestión y Planificación del Agua "Ríos Ibéricos+ 10: Mirando al futuro tras 10 años de DMA". Talavera de la Reina: CIGPA, 15 pp, 2011.

PASSOS, E. Fitogeomorfología y analisis ambiental. Raega-O Espaço Geográfico em Análise, v.1, p.143-158, 1997.

PERUCCA, E., CAMPOREALE, C., y RIDOLFI, L. Significance of the riparian vegetation dynamics on meandering river morphodynamics. Water Resources Research, v.43, n.3, 2007.

SANDERCOCK, P. J., HOOKE, J. M., Y MANT, J. M. Vegetation in dryland river channels and its interaction with fluvial processes. Progress in Physical Geography, v.31, n.2, p.107-129, 2007.

SANHUEZA, C., GERMAIN, P., ZAPPERI, G., PIOVAN, M. J., CUEVAS, Y., y TIZÓN, R. Plantas nativas de Bahía Blanca y sus alrededores. Tellus, Bahía Blanca, 204 pp, 2014.

SCIAN, B. Episodios ENSO y su relación con las anomalías de precipitación en la pradera pampeana. Geoacta, v.25, p.23-40, 2000.

SERENO, C. A. Procesos socioambientales en un espacio de borde. Estrategias de los actores en el rururbano bahiense. Tesis Doctoral. Universidad Nacional del Sur, Bahia Blanca, 2017.

SURIAN, N., BARBAN, M., ZILIANI, L., MONEGATO, G., BERTOLDI, W., y COMITI, $F$. Vegetation turnover in a braided river: frequency and effectiveness of floods of different magnitude. Earth Surface Processes and Landforms, v.40, n.4, p.542-558, 2015.

TAL, M., y PAOLA, C. Effects of vegetation on channel morphodynamics: results and insights from laboratory experiments. Earth Surface Processes and Landforms, v.35, n.9, p.1014-1028, 2010.

TOMSETT, C. y LEYLAN, J. Reach scale analysis of riparian vegetation interactions with fluvial morphology using UAV based laser scanning and multispectral imaging. In EGU General Assembly Conference Abstracts, p.35 - 94, 2020.

URRIZA, G. Procesos de producción y transformación del espacio periurbano del sector noreste de Bahía Blanca. Tesis Doctoral. Universidad Nacional del Sur, Bahia Blanca, 1998.

VILAN OVA, I., y PRIETO, A. R. Historia de la Vegetación de Las Llanuras Costeras de la Bahía Samborombón $\left(\sim 35,5^{\circ} \mathrm{s}\right)$, Argentina, Desde $7800{ }^{14} \mathrm{C}$ Años. Ameghiniana, v.49, n.3, p.303-318, 2012. 
VERETTONI, H. N. Las asociaciones halófilas del Partido de Bahía. Técnica y economía, v.4, n.11, p.41-65, 1950. 